\title{
Concept of care shock during intensive care unit discharge process
}

\author{
Dong Hyun Lee \\ Department of Intensive Care Medicine, Dong-A University Hospital, Busan, Korea
}

Discharging patients from the intensive care unit (ICU) and moving then to the general ward (GW) is a positive sign of clinical improvement after proper ICU management. However, at the time of ICU discharge, patients depart from close monitoring and expert care. Although the clinical course of patient improvement is continuous, the transition from the ICU to the $\mathrm{GW}$ is phased. The patients should overcome the sudden step-down process of care.

Some patients fail to adapt to the change and approximately $10 \%$ of ICU discharged patients are readmitted to the ICU [1]. Previous studies have focused on the step-down process and tried to identify risk factors for failure to adapt [2]. These studies sought to discriminate between patients who would and would not overcome the transition.

A qualitative study in Acute and Critical Care [3] described the experience of patients and their family during the rapid transition process. The authors collected the experiences of patients, families and members of the medical team in a narrative manner and specifically analyzed the transition from a patient's perspective. After thorough analysis, the authors regarded the upheaval process of transition as a "gap" that the patients and their family members have to overcome and endure. This gap in monitoring level, training level of the medical team, and environment can be accepted as an upheaval in care. The authors introduced a novel term for the gap that the patients and family experience in the transition process from the ICU to the GW: "care shock."

People experience "culture shock" when they arrive in a different society. This consists of uncertainty, confusion, anxiety, and other feelings related to unfamiliarity. Patients transferring from the ICU to the GW might also experience such feelings. This concept of "care shock" is a useful depiction of this transition from a patient's perspective.

To reduce the ICU readmission rate and to identify risk factors for readmission, many strategies such as predictive scores and follow-up programs have been suggested. However, further understanding of the care shock experience of patients is also needed.

\section{CONFLICT OF INTEREST}

No potential conflict of interest relevant to this article was reported.

\section{ORCID}

Dong Hyun Lee

http://orcid.org/0000-0001-6253-3396

\section{Editorial}

Received: February 21, 2021

Accepted: February 22, 2021

Corresponding author

Dong Hyun Lee

Department of Intensive Care

Medicine, Dong-A University

Hospital, 26 Daesingongwon-ro,

Seo-gu, Busan 49201, Korea

Tel: +82-51-240-2922

Fax: +82-51-242-5852

E-mail: icu1@dau.ac.kr

Copyright () 2021 The Korean Society of Critical Care Medicine

This is an Open Access article distributed under the terms of Creative Attributions Non-Commercial License (https:// creativecommons.org/li-censes/by-nc/4.0/) which permits unrestricted noncommercial use, distribution, and reproduction in any medium, provided the original work is properly cited. 


\section{REFERENCES}

1. Ofoma UR, Dong Y, Gajic O, Pickering BW. A qualitative exploration of the discharge process and factors predisposing to readmissions to the intensive care unit. BMC Health Serv Res 2018;18:6.

2. Stelfox HT, Lane D, Boyd JM, Taylor S, Perrier L, Straus S, et al.
A scoping review of patient discharge from intensive care: opportunities and tools to improve care. Chest 2015;147:317-27.

3. Ghorbanzadeh K, Ebadi A, Hosseini M, Madah SS, Khankeh $H$. Challenges of the patient transition process from the intensive care unit: a qualitative study. Acute Crit Care 2021;36:13342. 